\title{
ENTRE O DILACERAMENTO E A ALEGRIA: CONSIDERAÇÕES SOBRE A VELHICE NA LITERATURA BRASILEIRA DE AUTORIA FEMININA
}

\author{
Between dilaceration and joy: considerations on old age in the brazilian literature of \\ female authority
}

\author{
Maria do Rosário Alves Pereira \\ https://orcid.org/0000-0002-4797-5724 (0) \\ Centro Federal de Educação Tecnológica de Minas Gerais, Belo Horizonte, \\ MG, Brasil. 30421-169 - delteccefetmg@gmail.com \\ Claudia Cristina Maia \\ https://orcid.org/0000-0001-5213-712X (1) \\ Centro Federal de Educação Tecnológica de Minas Gerais, Belo Horizonte, \\ MG, Brasil. 30421-169 - delteccefetmg@gmail.com
}

\begin{abstract}
Resumo: Este artigo apresenta um breve estudo sobre a velhice feminina representada na literatura brasileira escrita por mulheres. Parte de um preâmbulo que procura informar sobre a ausência do tratamento dessas personagens em nossa literatura para depois analisar narrativas curtas (contos e minicontos) das seguintes escritoras: Clarice Lispector, Lygia Fagundes Telles, Cíntia Moscovich e Alê Motta. A análise é ancorada no pensamento de Simone de Beauvoir, Natalia Ginzburg, Eurídice Figueiredo, Carmen Lucia Tindó Secco e outras pesquisadoras, que apresentam importantes reflexões sobre a velhice, com destaque para a questão da solidão, que se mostrou recorrente nas narrativas selecionadas para o corpus, mas tratada de forma distinta em cada uma delas. A intenção não é traçar um panorama de tais representações, o que demandaria um estudo de mais fôlego, mas apontar algumas recorrências e particularidades quanto à temática, sobretudo no que toca à autoria feminina. Saliente-se que o tema da velhice faz-se pertinente para a análise pois é pouco estudado na literatura brasileira em geral, o que aponta para a relevância desta investigação.
\end{abstract}

Palavras-chave: Velhice; Solidão; Feminismo; Literatura Brasileira.

Abstract: This paper presents a brief study on the female old age represented in the Brazilian literature written by women. It starts with a preamble that seeks to inform about the lack of treatment of these characters in our literature, and then analyzed short narratives (stories and mini-stories) by the following writers: Clarice Lispector, Lygia Fagundes Telles, Cíntia Moscovich and Alê Motta. The brief analysis is supported by the thoughts of Simone de Beauvoir, Natalia Ginzburg, Eurídice Figueiredo, Carmen Lucia Tindó Secco and other researchers, who in their texts present important reflections on old age, with emphasis on the question of loneliness, which has been recurrent in the selected narratives, but different way in each of them. The intention is not to draw a panorama of such representations, which would require a more thorough study, but to point out some recurrences and particularities regarding the theme, especially with regard to female authorshiplt is important to point that the theme of old age is relevant to the analysis because it is not so much studied in Brazilian literature in general, which points to the relevance of this research.

Keywords: Old age; Loneliness; Feminism; Brazilian literature. 
É preciso que se saiba. É preciso que se saiba. Que a vida é curta. Que a vida é curta.

Clarice Lispector

Assunto tabu na sociedade brasileira, o envelhecimento, sobretudo o feminino, vem sendo relegado a segundo plano na literatura nacional. Isso é notório pela escassez de contos e romances que abordam a problemática. Conforme destaca Regina Dalcastagnè (2005), é perceptível um "mapa de ausências" em nossa literatura: há muitas lacunas no que se refere tanto à presença autoral propriamente dita - o número de autores homens, brancos, heterossexuais e residentes no eixo geográfico Rio de Janeiro-São Paulo é consideravelmente mais expressivo do que outros segmentos ${ }^{1}$ - quanto no que diz respeito às representações literárias. Desse modo, o tipo e a quantidade de personagens prototípicos do romance nacional são limitados e apontam para alguns modelos ou mesmo estereótipos já consagrados, como o do velho decrépito ou avarento. ${ }^{2}$ Tal decrepitude se dá em virtude do desprestígio do velho em um sistema capitalista ou ainda de fatores associados à degenerescência física.

Luci Ruas Pereira (2001) relembra na literatura infantil, por exemplo, a figura de Dona Carochinha no Sítio do Pica-Pau Amarelo, de Monteiro Lobato (série de 23 volumes publicados entre 1920 e 1947, posteriormente adaptada como série para a televisão), e o modo como Narizinho se referia às senhoras com as quais morava, chamando-as de "corocas". Há, ainda, representações do silenciamento feminino em narrativas contemporâneas, como é o caso de A ponta do silêncio, de Valesca de Assis, publicado em 2016, e A menina de véu, de Natália Nami, publicado em 2014. Outro exemplo é o romance de Carola Saavedra, Com armas sonolentas (2018), que apresenta uma personagem confinada em um asilo: a velha empregada doméstica estuprada pelo patrão e desprezada pela filha. Porém, destaque-se também outro tipo de representação que foge a essa visão de desvalorização, ainda que, quase sempre, isso apareça em personagens secundárias na trama: a do velho (ou velha) digno de respeito por seu saber ou experiência adquiridos: ${ }^{3}$ Carmen Lucia Tindó Secco (1994) observa outro horizonte sobre a representação da personagem da mulher velha no imagináro social, como a do romance Menino de engenho, de José Lins do Rego (1932), em que a velha Totonha é figura marcante nas memórias do menino Carlinhos, por sua contação de histórias, pelo poder encantatório da narração. Tais

\footnotetext{
${ }^{1}$ A pesquisa de Dalcastagnè, realizada entre 1990 e 2004, trouxe os seguintes dados: $72,7 \%$ dos autores eram homens; $93,9 \%$, brancos; e mais de $60 \%$ residentes em São Paulo ou no Rio de Janeiro. Destaque-se que, nas últimas décadas, houve um crescimento do segmento editorial independente no Brasil, possibilitando que autores situados à margem do campo literário pudessem publicar.

2 Simone de Beauvoir (2018) chama a atenção para uma série de representações caricatas do velho ao longo da história da humanidade, sobretudo na Idade Média, as quais destacavam, além de suas incapacidades físicas, seu apego excessivo aos bens materiais.

${ }^{3} \mathrm{O}$ conhecimento e as vivências dos velhos parecem ter outra dimensão na literatura negra, em que a ancestralidade é valorizada como elo e herança entre as gerações, como se lê no conto "Olhos d'água", de Conceição Evaristo (2014). Tal questão não é objeto de análise deste texto, contudo.
} 
exemplos apontam para o fato de que raramente o tema da velhice ocupa lugar central nas narrativas.

O protagonismo feminino é sempre secundário na ficção escrita por homens, ocupando sempre os mesmos lugares: donas de casa ou empregadas domésticas (sobretudo se se trata da mulher negra) confinadas, de um jeito ou de outro, ao espaço doméstico, e mulheres jovens com pinceladas de hiperssexualidade. Dalcastagnè (2005) destaca a relativa baixa presença de mulheres adultas e maduras no romance brasileiro atual: quando aparecem, a ênfase raramente se dá sobre questões ou dilemas ligados ao universo feminino e sim sobre "o casal romântico formado pelo galã maduro e pela mulher muito mais jovem" (2005, p. 38). Tal citação leva também à percepção de que o homem velho e a mulher velha não são considerados da mesma forma em nossa sociedade, haja vista que o homem, quanto mais velho, mais "charmoso" ou "experiente" aparenta ser, ao passo que a mulher perde seu valor, pois já não se presta a ser objeto de desejo alheio, nem é mão de obra produtiva para o sistema capitalista. Dessa forma, sua subalternização é muito mais evidente do que a masculina, restando-lhe papéis como, por exemplo, o da "avó profissional" - mulheres que abdicam da própria vida para cuidarem dos netos. ${ }^{4}$

Simone de Beauvoir (2018) questiona a idade para o envelhecimento conforme a cultura e o período histórico. Ela salienta que essa problemática está relacionada à questão do poder na sociedade, e, por isso, sempre se deu no interior das classes dominantes "Até o século XIX, nunca se fez menção aos 'velhos pobres"” (2018, p. 94). A filósofa francesa completa:

Um outro fato salta aos olhos: trata-se aí de um problema de homens. Enquanto experiência pessoal, a velhice concerne tanto a eles quanto às mulheres, e mesmo mais ainda a estas últimas, pois vivem mais tempo. Mas quando se faz da velhice um objeto de especulação, considera-se essencialmente a condição dos machos. Primeiro, porque são eles que se exprimem nos códigos, nas lendas e nos livros; mas sobretudo porque a luta do poder só interessa ao sexo forte. [...] as mulheres jovens e velhas podem até disputar a autoridade na vida privada; na vida pública, seu estatuto é idêntico; são eternas menores. (BEAUVOIR, 2018, p. 94-95).

Em conformidade com o texto supracitado, a mulher velha não interessa como tema, como assunto de discussão, seja este ligado ao campo político, econômico e, inclusive, cultural. Socialmente, não é difícil perceber que as mulheres velhas são relegadas a segundo plano: ${ }^{5}$ basta uma rápida olhada pelos comerciais de TV ou ainda um flerte com redes sociais como o Instagram para perceber o quanto nossa sociedade é focada em apelos à manutenção de um corpo belo e magro e no quanto é notório o movimento de toda uma indústria - de alimentos, de cosméticos, de cirurgias plásticas etc. - para convencer as pessoas da importância de se manterem joviais. Segundo o relatório da IHRSA Global

\footnotetext{
${ }^{4}$ No romance Quarenta dias, de Maria Valéria Rezende (2016), desenvolve-se esta problemática.

${ }^{5}$ Beauvoir (2018) chama a atenção, já nos anos de 1970, para o descaso social em relação ao idoso, o que seria surpreendente, uma vez que "cada membro da coletividade deveria saber que seu futuro está em questão" (2018, p. 227).
} 
Report 2019, o Brasil tem se mantido na posição de segundo maior mercado do mundo no que se refere ao número de academias, com mais de trinta mil estabelecimentos neste segmento (em 2007, o país contava com pouco mais de 7 mil). Além disso, o Brasil é o país do mundo que mais realiza cirurgias plásticas, tendo ultrapassado os Estados Unidos. Como se percebe, trata-se de uma questão cultural arraigada na sociedade brasileira: o excesso de valorização do corpo e da aparência conduz, em seu lado oposto, ao descarte de milhares de corpos que não se adaptam aos moldes estabelecidos como ideais. Conforme Eurídice Figueiredo:

Vivemos sob o signo da juventude. A mudança de costumes desencadeada nos anos 1960 reforçou o ethos da juventude, cujo padrão de beleza inferniza todas as mulheres que se submetem a ele através de cirurgias plásticas e demais procedimentos estéticos. Não existe moda adequada para velhas [...]. Aquela sabedoria dos velhos de que falava Benjamin não tem mais lugar num mundo em que eles não conseguem acompanhar os avanços tecnológicos. (FIGUEIREDO, 2020, p. 241).

Invisível socialmente, o velho também o é na literatura, e, mais ainda, a mulher velha. Em um lúcido ensaio sobre a velhice escrito em 1968, Natalia Ginzburg argumenta que a velhice nunca nos inspirou um profundo interesse ou curiosidade; e, para exemplificar, ela lembra - e essa lembrança é desconcertante para todos nós, mulheres e homens, velhos e jovens - que na história clássica Chapeuzinho vermelho, "o personagem que nos suscitava menos curiosidade era a avó, e que não nos importava de fato que ela saísse salva da barriga do lobo"6 (GINZBURG, 2002, posição 293, tradução nossa).

Para o presente texto, foram selecionados alguns contos e minicontos de escritoras brasileiras que trazem em suas narrativas a temática da velhice. Em "Feliz aniversário" e "O grande passeio", de Clarice Lispector (2009, 1998), fica clara a infantilização e a falta de um lugar - não somente físico, mas, sobretudo, social - a ser ocupado pelas mulheres velhas; em "Boa noite, Maria", de Lygia Fagundes Telles (1998a), tem-se uma mulher idosa à procura de um companheiro que pudesse auxiliá-la quando chegasse o momento derradeiro da morte; em "O reino das cebolas", de Cíntia Moscovich (2002), uma dona de casa, já avó, descobre nos cuidados ao neto um refrigério para sua rotina estafante; e, finalmente, nos minicontos de Alê Motta (2020), retirados da obra Velhos, observa-se uma mudança no enfoque da temática: se até os anos de 1990 a tônica parece ser a de reforçar a solidão e o corpo feminino envelhecido como silenciado e degradado, na última década há que se considerar representações da velhice que, ao contrário, apontam para alegrias possíveis e para um remanejamento das relações sociais. Destaque-se que a escolha deste corpus pretende apontar distintas percepções da velhice feminina na literatura produzida por mulheres, no Brasil, ao longo do tempo; no entanto, é sabido da impossibilidade de se esgotar todas as leituras sobre o tema ou, ainda, de se traçar um panorama de tais

\footnotetext{
6 "il personaggio che meno ci incuriosiva era la nonna, e non ci importava affatto che uscisse salva dal ventre del lupo" (GINZBURG, 2002, posição 293).
} 
representações no espaço exíguo de um artigo.

O conto "Feliz aniversário", do livro Laços de família, publicado em 1960, narra o dia da festa de aniversário de 89 anos da matriarca - nomeada de aniversariante, mãe e velha - de uma família carioca. A aniversariante morava na casa da filha Zilda, que organizara a festa - "a única mulher entre os seis irmãos homens e a única que, estava decidido já havia anos, tinha espaço e tempo para alojar a aniversariante" (LISPECTOR, 2009, p. 55). Desde o primeiro parágrafo do conto, a narrativa destaca os problemas que a família vive e que, como em toda família, grande ou pequena, ficam evidentes em dias de reuniões e comemorações:

A família foi pouco a pouco chegando. Os que vieram de Olaria estavam muito bem vestidos porque a visita significava ao mesmo tempo um passeio a Copacabana. A nora de Olaria apareceu de azul-marinho, com enfeite de paetês e um drapeado disfarçando a barriga sem cinta. O marido não veio por razões óbvias: não queria ver os irmãos. Mas mandara sua mulher para que nem todos os laços fossem cortados - e esta vinha com o seu melhor vestido para mostrar que não precisava de nenhum deles, acompanhada dos três filhos: duas meninas já de peito nascendo, infantilizadas em babados cor-de-rosa e anáguas engomadas, e o menino acovardado pelo terno novo e pela gravata. (LISPECTOR, 2009, p. 54).

O excerto traz elementos importantes para o entendimento do conto: as personagens são identificadas pelos bairros em que moram na cidade do Rio de Janeiro: a mãe em Copacabana, bairro tradicional da zona sul; uma nora em Olaria, na zona norte da cidade; outra nora, como se lê adiante no conto, em Ipanema. Por essa demarcação percebe-se a classe social de cada uma delas e presume-se algum dos motivos dos desentendimentos familiares. Há também um destaque para suas vestimentas, de tal forma que se pode tomálas até mesmo como figurinos, dado o componente "teatral" e de superficialidade que reveste a cena. A caracterização das crianças - infantilizadas as meninas e acovardado o menino - é a mesma dos adultos, como se pode concluir ao longo da narrativa. A família vive uma relação de aparências e os filhos e noras estão na festa de aniversário da mãe apenas para cumprir uma obrigação, para "manter os laços", como a sociedade pressupõe e determina. Nesse cenário, a mãe, que já é bisavó, parece não ter desejos ou opinião, é um joguete, um objeto como qualquer outro usado para decorar o ambiente da festa. Em meio aos "guardanapos coloridos", aos balões que pendem do texto, ao "bolo açucarado" no centro da mesa, arrumada pela filha como se fosse ela a exercer este papel, a mãe espera não sabe o quê:

E, para adiantar o expediente, vestira a aniversariante logo depois do almoço. Pusera-lhe desde então a presilha em torno do pescoço e o broche, borrifara-lhe um pouco de água-de-colônia para disfarçar aquele seu cheiro de guardado - sentara-se à mesa. $E$ desde as duas horas a aniversariante estava sentada à cabeceira da longa mesa vazia, tesa na sala silenciosa. (LISPECTOR, 2009, p. 55).

O sentimento que vive a protagonista é de angústia, uma "angústia muda", e durante 
quase todo o tempo da festa ela permanece em silêncio, impassível, sentada à cabeceira da mesa. Em um determinado momento, o narrador denomina-a velha e, tal qual descrevesse um retrato antigo, apresenta uma espécie de síntese da personagem, de como a família a via: "Tratava-se de uma velha grande, magra, imponente e morena. Parecia oca" (LISPECTOR, 2009, p. 60). A protagonista se mexe apenas quando pisca e quando chega o momento de partir o bolo e ela o faz com um "punho de assassina" (LISPECTOR, 2009, p. 59). O sentimento de angústia, vivido em função da solidão, se transforma em desprezo e rancor. Ao observar silenciosa a família, ela se dá conta daquilo que eles se tornaram: "azedos e infelizes frutos, sem capacidade sequer para uma boa alegria", "seres risonhos, fracos, sem austeridade", "ratos se acotovelando" (LISPECTOR, 2009, p. 60). E ela tem uma reação, que vem de uma "força insuspeita": cospe no chão. O movimento é visto pela família como uma malcriação infantil, e a filha Zilda se sente envergonhada e ao mesmo tempo culpada, pois a ela tinha sido "imposta" a tarefa de "educar" a mãe idosa que tinha voltado a ser criança. A esta reação se segue uma outra: ela ordena um copo de vinho, em tom autoritário e cheio de impropérios, em função da resistência da família ao seu desejo de beber. Essas reações da personagem provocam na família, primeiramente, um susto, que logo se desfaz; toda artificialidade da convivência (ou não convivência) é retomada e a aniversariante, "mãe de todos", retorna ao seu estado de sempre: o silêncio. De acordo com Maria do Rosário A. Pereira (2019), retomando ideias expressas por Beauvoir em A velhice e incorporando-as na leitura deste conto,

Muitas vezes, atitudes consideradas estranhas por parte dos velhos, como descuidos em relação à higiene, por exemplo, nada mais são do que reações a essa tirania, como forma de autodefesa ou mesmo vingança. Tal consideração parece dar a dimensão exata da postura de D. Anita que, subitamente, altera seu comportamento. (PEREIRA, 2019, p. 6).

Nesse conto, Clarice chama a atenção para o fato de a sociedade tomar os velhos apenas pela aparência do que são: pessoas que não pensam, que não têm desejos e, nesse contexto, o que lhes resta é a solidão e a mudez: dona Anita (o nome da personagem é falado apenas por uma vizinha no momento de saudá-la na hora do canto de parabéns), "nunca mais ela seria apenas o que ela pensasse. Sua aparência afinal a ultrapassara e, superando-a, se agigantava serena" (LISPECTOR, 2009, p. 64). A única que se dá conta desse lugar da velhice é uma das noras, Cordélia, que olha a sogra e vê nela não só sua infelicidade, mas a de todo velho e, portanto, também a sua, que virá em um futuro breve: "culpada, perplexa e desesperada [...] mais uma vez olhou para trás implorando à velhice ainda um sinal de que uma mulher deve, num ímpeto dilacerante, enfim agarrar a sua derradeira chance e viver" (LISPECTOR, 2009, p. 64). A protagonista, contudo, se encerra em sua vida solitária, cheia de preconceitos, resignada com a vida de aparências, fingindo não reconhecer a ausência do carinho verdadeiro da família, como à espera da morte. "A morte era o seu mistério" (LISPECTOR, 2009, p. 64). Com essa frase termina a narrativa e a lúcida reflexão de Lispector (2009). 
Em conto publicado posteriormente, a princípio com o título "Viagem a Petrópolis", em A legião estrangeira, de 1964, e depois com novo título, "O grande passeio", em Felicidade Clandestina, de $1971,{ }^{7}$ a protagonista velha não é mais uma mulher da classe média alta do Rio de Janeiro, mas uma mulher pobre vinda do estado do Maranhão, que vivia de caridade em casas de outrem. A despeito da diferença de classe, ainda é a solidão - e o silêncio decorrente dela - o grande tema da narrativa. A vida anterior de Mocinha, nome pelo qual ela se identificava, em contraste claro com sua idade, o que provoca o riso das pessoas, não é narrada; apenas alguns fatos são mencionados, bem esparsamente. Ela chegara ao Rio em companhia de uma senhora que pretendia interná-la em um asilo, mas não o fez, pois precisou viajar para Minas, deixando a velha mais uma vez sozinha. Além da solidão, o que chama a atenção na personagem é a "não percepção", que não é apenas um simples desentendimento, ou um simples demorar-se para entender, mas também um desejo de não entender:

Era uma velha sequinha que, doce e obstinada, não parecia compreender que estava só no mundo. Os olhos lacrimejavam sempre, as mãos repousavam sobre o vestido preto e opaco, velho documento de vida. No tecido já endurecido encontravam-se pequenas crostas de pão coladas pela baba que lhe ressurgia agora em lembrança do berço. Lá estava uma nódoa amarelada, de um ovo que comera há duas semanas. $\mathrm{E}$ as marcas dos lugares onde dormia. Achava sempre onde dormir, casa de um, casa de outro. Quando lhe perguntavam o nome, dizia com a voz purificada pela franqueza e por longuíssimos anos de boa educação: - Mocinha. (LISPECTOR, 1998, p. 29).

Da mesma forma do conto analisado anteriormente, aqui também a descrição apresentada no primeiro parágrafo informa muito sobre a personagem: suas roupas são o que ela é, uma velha abandonada e opaca. Os olhos que lacrimejavam constantemente parecem de um choro contido, um choro que se esqueceu de cair. Ela era a única sobrevivente da família depois da morte dos pais, marido e dois filhos. Mocinha passa então a viver só e de favores. Morava em uma casa grande em Botafogo, "não se sabia mais por que motivo", e tinha como hábito acordar cedo e sair a andar, a "passear" pela cidade. Os passeios, ao que parece, preenchiam o seu tempo e talvez a livravam da percepção da solidão. Em um determinado dia a família de Botafogo decide mandá-la para a casa de um parente deles, uma cunhada alemã, em Petrópolis. A mudança foi planejada e Mocinha, na noite anterior à viagem, não dormiu: "À ideia de uma viagem, no corpo endurecido o coração se desenferrujava todo seco e descompassado [...]. A excitação do passeio prometido e a mudança de vida, de repente, aclararam algumas ideias" (LISPECTOR, 1998, p. 31). O grande passeio não era como os passeios rotineiros, mas parecido com aquele que fizera quando se mudara para o Rio e, provavelmente por isso, provocou-lhe lembranças da vida passada: o filho morto atropelado e a filha morta no parto. Com as lembranças, ela começa

\footnotetext{
7 Optamos por usar o título "O grande passeio", uma vez que a mudança foi escolha da escritora e porque o vocábulo passeio (repetido algumas vezes na narrativa e de forma muito significativa), antecipado pelo adjetivo grande, nos parece mais emblemático.
} 
a tomar consciência da vida: de que a cama que dorme é dura, de que está com fome, de que vive só. A mudança ou a possibilidade dela ativa a memória, que suscita a percepção, o início do entendimento. Mocinha tinha sido levada para a casa de um dos filhos da família, que morava em Petrópolis com a esposa alemã, mas ele, que não sabia da "encomenda", não a aceita, manda-a dizer à família que a casa dele não era asilo. Mocinha dirige-se para a estrada e começa um passeio; para em um chafariz a fim de matar a sede, continua a caminhada e morre:

Saciada, espantada, continuou a passear com os olhos mais abertos, em atenção às voltas violentas que a água pesada dava no estômago, acordando pequenos reflexos pelo resto do corpo como luzes. A estrada subia muito. A estrada era mais bonita que o Rio de Janeiro, e subia muito. Mocinha sentou-se numa pedra que havia junto de uma árvore, para poder apreciar. O céu estava altíssimo, sem nenhuma nuvem. E tinha muito passarinho que voava do abismo para a estrada. A estrada branca de sol se estendia sobre um abismo verde. Então, como estava cansada, a velha encostou a cabeça no tronco da árvore e morreu. (LISPECTOR, 1998, p. 3738).

O grande passeio não era exatamente o que fez para Petrópolis, mas aquele anunciado pela longa estrada que avistava, em uma subida sem fim. A morte de Mocinha, diferentemente da morte anunciada no conto anterior - misteriosa e esperada com amargura - é uma morte doce, como a própria Mocinha é descrita na primeira linha da narrativa: "doce e obstinada". Quando a personagem passa a compreender que vive uma vida só e miserável, de total desamparo, ela como que decide morrer. A morte aqui é, portanto, libertação e alternativa à solidão da velhice. A personagem torna-se pedra, se usarmos o argumento de Natalia Ginzburg (2002). Segundo a escritora italiana, ao longo dos anos, "pouco a pouco vamos caindo na imobilidade da pedra" e isso provoca uma "substancial indiferença em nos submetermos a um novo estado", que é a ausência, a incapacidade de nos espantarmos, conosco mesmo e com os outros, com tudo que há ao nosso redor (2002, posição 312, tradução nossa). ${ }^{8}$

O conto "O reino das cebolas", que dá título ao livro de Cíntia Moscovich publicado em 1999, e que tem como epígrafe um trecho do conto "Amor", de Lispector, é narrado como a predizer uma ação futura da personagem, uma senhora, Dona Eugência, que tem uma vida de dona de casa. Ela vive no reino das cebolas, o reino da cozinha, em que tudo passa a cheirar cebola. Contudo, a narrativa propõe um escape: cuidar do neto, diferentemente do que é para muitas avós - aprisionamento e exploração, como representado no romance Quarenta dias, de Maria Valéria Rezende (2014) -, torna-se uma atividade extremamente prazerosa, um alívio, uma fuga do reino das cebolas. E enquanto todas as mulheres estarão cortando cebolas, "todas no mesmo exercício, [...] todas chorando lágrimas ácidas para o bem do arroz ou do refogado ou da carne. Todas pelo

\footnotetext{
8 "poco a poco veniamo cadendo nell'immobilità della pietra", "la nostra sostanziale indifferenza nel sottostare a un simile nuovo stato" (GINZBURG, 2002, posição 312).
} 
bem da comida, a que sempre tiveram de forjar dos sucos do próprio corpo, da habilidade das próprias mãos" (MOSCOVICH, 2002, p. 85), Dona Eugênia brincará com o neto na sala:

E a senhora vai estar feliz, muito feliz, Dona Eugênia, porque o cheiro das cebolas terá ido embora e porque a senhora vai descobrir a única companhia possível, o único ser que não esqueceu o primário essencial, o único dos seus que valeu as lágrimas de cebola que a senhora chorou. E, então, enfim, a senhora vai saber. (MOSCOVICH, 2002, p. 87).

Para brincar com o neto, a personagem abandona a tarefa perpétua e repetitiva de cozinhar para a família. Há, portanto uma ruptura com relação aos padrões sociais do que se espera de uma mulher velha, ainda que a alternativa continue no ambiente doméstico e familiar. Há uma busca pela felicidade, uma fuga da solidão, do tédio que acomete a velhice. Dona Eugênia é capaz de assim caminhar para a morte com alegria. "Ela apaziguara tão bem a vida, cuidara tanto para que esta não explodisse", preconiza as palavras de Lispector no início do conto.

"Boa noite, Maria", de Lygia Fagundes Telles, foi publicado na coletânea $A$ noite escura e mais eu, cuja primeira edição data de 1995. Nos anos de 1990, muitas foram as mudanças a se processarem na literatura escrita por mulheres no Brasil: após passar por um período de extensa crítica ao patriarcado, sobretudo nos anos de 1960 e 1970, na década de 1980 esse topos parece se alterar, e a busca da mulher por um espaço social torna-se mais contundente. ${ }^{9}$ Ainda que a produção seja muito variada, é possível destacar que, sobretudo nos anos de 1990, a questão da autodescoberta feminina, em expressão de Elódia Xavier (1996), é, de fato, o mote central, autodescoberta esta manifesta de formas variadas pelas escritoras.

É justamente neste cenário que vem à luz a referida obra de Fagundes Telles (1998a). No conto "Boa noite, Maria", é narrada a história de uma mulher riquíssima, Maria Leonor de Bragança, que desembarca no aeroporto e, ao ser auxiliada por um homem de aproximadamente 50 anos que lhe carrega as malas, acaba por convidá-lo a hospedar-se em seu apartamento. $O$ peso da velhice para a personagem é perceptível logo nas primeiras linhas do conto: "Ele deixou as malas na calçada, próximas da longa fila de carros, e pela primeira vez a encarou. Instintivamente a mulher encolheu-se, esquivava-se das avaliações desde que completou sessenta anos." (TELLES, 1998, p. 58). Quanto às intenções do convite realizado, por meio da autorreflexão da protagonista desnudam-se uma série de questões, já que ela pretendia dividir o silêncio com alguém capaz de ajudá-la a suportar "o peso da solidão":

Oh! Senhor, chega de cama, amante não. Tanto cansaço, um cansaço que

\footnotetext{
${ }^{9}$ Como exemplo, tem-se a obra produzida por Sônia Coutinho, a qual apresenta personagens femininas às voltas com dilemas existenciais ligados à permanência no cerne doméstico e à consequente manutenção de costumes e, ao mesmo tempo, lidando com anseios pessoais de buscar outros espaços e outras formas de realização pessoal. (XAVIER, 1996).
} 
vinha de longe, tanta preguiça. Ter que entrar novamente na humilhante engrenagem do rejuvenescimento, que mão-de-obra. Era alto demais o preço para escamotear a velhice, neutralizar essa velhice - até quando? Por favor, quero apenas assumir a minha idade, posso? Simplesmente depor as armas, coisa linda de se dizer. E fazer. O tempo venceu, acabou. Até que chegou a reagir, recorreu a uma plástica, coisa leve, tinha quarenta anos e um amante vaidoso. Mas querida, você precisa de uma refrescada! A expressão estava na moda, refrescada. Obedeceu. Mas depois desse Augusto veio o Horácio. Ou foi o Rafael? E as insinuações recomeçando, não estaria na hora de apagar o vinco da boca? [...] (TELLES, 1998, p. 64).

O trecho é elucidativo no que se refere às cobranças sociais impostas à mulher e à falsa necessidade de adequação aos padrões de beleza vigentes. ${ }^{10}$ Tais padrões aparecem indissociavelmente ligados, como visto no excerto, à manutenção da sexualidade feminina ativa e à presença de seu corpo como um corpo ainda aprazível e predisposto a saciar os desejos masculinos. A personagem do conto lygiano, agora na maturidade, ao fazer um balanço sobre o quanto essas falsas necessidades tornam-se exaustivas com o tempo, acaba por render-se ao inexorável: a passagem do tempo que culmina na morte. Afinal, conforme Beauvoir, "velhice é um destino, e quando ela se apodera da nossa própria vida, deixa-nos estupefatos" (2018, p. 297). Apesar desse sentimento de certa surpresa que, em geral, se apodera das pessoas quando chega a velhice, ao não ceder mais aos apelos do mundo que a rodeia, a personagem Maria resiste ao sistema. De acordo com Silvana Vilodre Goellner (2008),

$\mathrm{Na}$ sociedade contemporânea nossos corpos são tornados espetáculos. São instituições performantes que, ao moverem-se, carregam muito mais que músculos, ossos e aparências. Carregam significados, tornam carne, representações e discursos que operam, no detalhe, o controle, a vigilância, o enquadrinhamento, a fixidez. $E$, também, a resistência, o descentramento, a transgressão. (2008, p. 246).

Maria também transgride quando leva para sua casa um completo desconhecido que conhece no aeroporto, ela com 65 anos de idade. É assim que o controle social - esboçado no conto pela lembrança que ela tem do doutor Jonas ao sugerir-Ihe um acompanhante dali pra frente - é duplamente driblado: primeiro, quando a personagem se nega a continuar alimentando o ciclo infinito de plásticas e outros mecanismos que aparentemente escamoteiam a velhice; em segundo lugar, ao invés de contratar um acompanhante profissional, um enfermeiro, ela o escolhe entre o rol de estranhos, intuitivamente, como ela própria descreve, pois não queria um mero acompanhante, mas sim um amigo.

Assim, o convite para que Julius fique em seu apartamento nada mais é do que a necessidade afetiva de preencher um vazio que há muito se instalara; na sequência, observa-se ainda a intenção da personagem de que alguém a ajudasse a morrer quando

\footnotetext{
10 "Referindo-se à cultura feminina dos anos 1950, [Betty] Friedan lamentou não haver 'nenhuma outra forma de uma mulher ser uma heroína' a não ser 'não parando de ter filhos'. Hoje em dia, uma heroína não pode "parar de ser linda'." (WOLF, 2018, p. 103)
} 
ela assim desejasse, pois, diante de alguns "antecedentes e presságios" (TELLES, 1998a, p. 71), ela temia que sua vida fosse prolongada em condições menos favoráveis. Afinal, conforme nos esclarece o narrador por meio do discurso indireto livre:

[...] a velhice já era a própria vulgaridade com seu rápido-lento processo de decomposição. [...] não tinha medo da velhice, mas daquele caudal de doenças degradantes que acompanham essa velhice, doenças que nem dão ao doente o simples direito de se matar. E se matar de que jeito se os braços estão paralisados e a mente é uma lâmpada que se apagou. (TELLES, 1998a, p. 68 e 70).

Passado um ano de convivência entre ambos, a saúde de Maria torna-se mais debilitada. E, numa bela cena, dá-se, finalmente, o enlace carnal entre ambos:

Aconteceu. E nesse mesmo sofá onde estava agora, bebiam vinho e assistiam a um filme sem maior interesse quando as mãos se apertaram com força mas sem aflição. As bocas se buscaram simplesmente e quando os corpos deslizaram abraçados para o chão, quando se juntaram nus em cima do tapete felpudo, ele disse apenas, sem pressa, fique calma. Obedeceu, conteve-se. Tanta ansiedade e ele exato, comandando até o final o gozo agudo. Intenso. Nunca sentira antes esse prazer assim desvairado [...] [então] fez a pergunta frívola, recorria à frivolidade como escape, Então, Julius? Vai querer me ver remoçada? [...] Ele demorou para responder. Afagou-lhe os cabelos. A sua beleza vem de dentro, Maria. Não se preocupe, ela resiste. (TELLES, 1998a, p. 75).

Nesta passagem, Maria volta à temática do rejuvenescimento. Percebe-se que o assunto, isto é, as sucessivas imposições por parte de antigos parceiros para que ela fizesse plásticas, ainda a assombra. No entanto, a natureza de sua relação com Julius era em tudo diferente do que ela havia experimentado até então, o que é corroborado pela intensidade do prazer sentido - muito provavelmente, era a primeira vez que se sentia valorizada como mulher, que se sentia amada enquanto sujeito, liberta das amarras da cultura fitness, ${ }^{11}$ que regula e educa os corpos femininos para que sirvam aos ideais do capital. Além disso, "só agora ela conhecera o próprio corpo num aprendizado tardio" (TELLES, 1998a, p. 75). O final do conto, em que ela adormece nos braços de Julius, é ambíguo: seria o sono da morte, apressada, talvez, por alguma substância que ele colocara em sua bebida? Ou Maria simplesmente adormecia nos braços do homem que, fielmente, permanecia a seu lado e com ela planejava um cruzeiro pelo Mediterrâneo? Permanece, como em muitos desfechos lygianos, o final em aberto, para que o leitor construa suas próprias hipóteses.

Também nos minicontos da escritora Alê Motta (2020), publicados na coletânea Velhos, aparecem formas de resistência ao status quo por parte de mulheres velhas.

\footnotetext{
${ }^{11}$ Segundo Goellner, cultura fitness, como parte da "estética do comedimento", é o "conjunto de dispositivos que opera em torno da construção de uma representação de corpo que conjuga como sinônimos saúde e beleza, associando-as a termos representados como plenos de positividades, dentre eles 'bem-estar', 'qualidade de vida' e 'vida saudável'”. (2008, p. 247).
} 
Ressalte-se que, nesta coletânea, são retratados diferentes aspectos da velhice, tanto masculina quanto feminina; porém, neste artigo, vamos analisar rapidamente contos cujas protagonistas são mulheres: "Solidão", "Listas" e "Emoções". Antes, porém, vale a pena diferenciar, mesmo que de modo breve, a forma "miniconto" do conto propriamente dito. De acordo com Erik Karl Schollhammer, é na década de 1990 que se consolida "a potência diferencial de outra experiência narrativa" (2009, p. 92):

[...] a preferência pelos minicontos e outras formas mínimas de escrita que se valem do instantâneo e da visualização repentina, num tipo de revelação cuja realidade tenha um impacto de presença maior. (SCHOLLHAMMER, 2009, p. 92).

Entretanto, a visualidade do miniconto não se restringe a essa semelhança com a velocidade e a instantaneidade da fotografia, mas se refere muito mais à concretude e à autossuficiência de um texto in media res, que parece não se apoiar sobre nenhuma realidade fora de si, pelo contrário, é uma parte avulsa dessa própria realidade, como um pequeno resíduo duro dos milhares de imagens e textos que compõem a trama de nosso cotidiano. (SCHOLLHAMMER, 2009, p. 93-94).

É assim que, se o próprio conto, como forma narrativa, já apresenta limitações no que se refere ao número de personagens e ao modo como as ações são narradas, ${ }^{12}$ o miniconto potencializa esse "flagra", sendo, então, um recorte ainda mais enxuto. O leitor não sabe o que precedeu a vida de uma personagem e, nem sempre, há pistas sobre o que está por vir; o que interessa, em sua potência máxima, é, de fato, o instante captado - e o miniconto deve sustentar-se sobre si mesmo nesse sentido.

Em "Solidão", a personagem não permite que a ausência de parentes ou amigos próximos dê relevo a sua solidão: "Visto uma roupa bonita e vou para a cafeteria do supermercado, perto de casa. [...] Tomo café com leite e torradas. Lentamente. Puxo conversa com todo mundo. [...] Só volto para casa quando me sinto feliz." (MOTTA, 2020, p. 77, grifo no original). O prazer de saborear a própria companhia, de preparar-se para este momento ao buscar um vestuário aprazível, não permite que sentimentos como angústia e depressão deem conformidade à vida da personagem. O advérbio em destaque aponta para a distinção entre temporalidades: o tempo do mundo, que impulsiona as pessoas a uma correria desenfreada em busca de objetivos quase sempre imediatistas e materiais; e o tempo dos velhos, à margem de imposições e cobranças e que, por isso mesmo, conseguem experienciar o tempo de uma forma mais profunda - antes corpo servil, predisposto a suprir as necessidades do sistema; agora, corpo autônomo, empenhado em atender a seus próprios anseios.

Dinâmica parecida a esta se dá no miniconto "Listas", narrado por uma mulher cujo

\footnotetext{
${ }^{12}$ Em entrevista, Lygia Fagundes Telles (1998b) discorre sobre as formas de cooptação dos leitores no gênero conto: "[...] eu preciso seduzir o leitor num tempo mínimo. Eu não vou ter a noite inteira para isso, com uísque, caviar, entende? Preciso ser rápida, infalível. O conto é, portanto, uma forma arrebatadora de sedução." (1998b, p. 29).
} 
casamento já chega a mais de 40 anos. Nas primeiras linhas, reitera o esquecimento recorrente e relata que, desde então, faz listas para cumprir seus afazeres. Após apresentar qual seria essa lista, composta por dez itens, afirma: "Não fiz metade da lista. Eu e meu velho estamos maratonando Stranger Things. O dia voou." (MOTTA, 2020, p. 85). Novamente, é o prazer que dá lugar às obrigações rotineiras: ao invés de lavar banheiros ou marcar exames, o casal prefere passar o dia assistindo a uma série. Em "Emoções", uma senhora de 89 anos sai de casa com o neto para votar pela primeira vez na vida. $E$ afirma: "Eu quero votar. É meu direito. Lembro da época que eu queria e não podia. Só os homens podiam." (MOTTA, 2020, p. 32). Neste miniconto, há uma referência à extensa luta pelo voto feminino, a qual se iniciou no século $X I X$, tendo se estendido até meados do $X X$, uma vez que somente em 1932 o Código Eleitoral assegurou esse direito às mulheres. $A$ personagem de Alê Motta (2020) faz questão de exercer esse direito e fica tão emocionada que quase chora. Tanto este quanto os outros minicontos apresentam uma reconfiguração do problema da velhice, sobretudo da velhice feminina: atualmente, em que o envelhecimento da população brasileira é cada vez maior, e em que se é considerado "velho" cada vez mais tarde, a chamada "terceira idade" parece estar redescobrindo seus direitos, suas necessidades e novas formas de aproveitar a vida, e a escritora Alê Motta dá atenção a isso em sua coletânea.

Nas narrativas analisadas, no que diz respeito à velhice feminina, o tema da solidão se mostrou recorrente, apesar de tratado de forma distinta em cada uma delas. Em Clarice Lispector, a solidão da mulher velha ora é acompanhada de angústia e ressentimento, ora de uma aceitação da morte como libertação. Em Lygia Faguntes Telles, a velhice é representada a partir de uma tentativa de contravenção às regras da sociedade, que impõem às mulheres velhas uma corrida contra o tempo. Em Cíntia Moscovich, por sua vez, essa contravenção se dá a partir de uma recusa ao universo da cozinha e uma afirmação do momento de prazer, ainda que este seja o cuidado com o neto. Na obra de Alê Motta, por fim, percebe-se uma maior reconfiguração da velhice, uma vez que suas personagens procuram driblar a solidão, abrindo-se para alegrias que vão além do univeso doméstico. Ainda que este estudo não tenha pretensão de traçar um panorama da representação da mulher velha na literatura de autoria feminina contemporânea, as análises mostram que essa literatura começa a dar sinais das transformações sociais, ainda que, destaque-se, essa reconfiguração em torno da velhice seja lenta e gradual.

\section{Referências}

BEAUVOIR, Simone de. A velhice. 2. ed. Rio de Janeiro: Nova Fronteira, 2018.

COLTRO, Pedro. O Brasil ultrapassou os Estados Unidos e se tornou o país que mais realiza cirurgias plásticas no mundo. SBPC Blog, 13 fev. 2020. Disponível em: http://www2.cirurgiaplastica.org.br/blog/2020/02/13/lider-mundial/. Acesso em: 26 nov. 2020. 
DALCASTAGNĖ, Regina. A personagem do romance brasileiro contemporâneo: 19902004. Estudos de Literatura Brasileira Contemporânea, Brasília, n. 26, p. 13-71, jul.-dez. 2005.

FIGUEIREDO, Eurídice. Por uma crítica feminista: leituras transversais de escritoras brasileiras. Porto Alegre: Zouk, 2020.

GINZBURG, Natalia. La vecchiaia. In: GINZBURG, Natalia. Mai devi domandarmi. Torino: Einaudi, 2002. E-book.

GOELLNER, Silvana Vilodre. A cultura fitness e a estética do comedimento: as mulheres, seus corpos e aparências. In: STEVENS, Cristina Maria Teixeira; SWAIN, Tânia Navarro (Org. ). A construção dos corpos: perspectivas feministas. Florianópolis: Ed. Mulheres, 2008, p. 245-260.

LISPECTOR, Clarice. Felicidade clandestina: contos. Rio de Janeiro: Rocco, 1998.

LISPECTOR, Clarice. Laços de família: contos. Rio de Janeiro: Rocco, 2009.

MOSCOVICH, Cíntia. O reino das cebolas. In: MOSCOVICH, Cíntia. O reino das cebolas. Porto Alegre: L\&PM, 2002. E-book.

MOTTA, Alê. Velhos. São Paulo: Reformatório, 2020.

PEREIRA, Luci Ruas. "Nas rugas do tempo": presença do velho na literatura infantil brasileira. COLE, 13. Campinas. Anais eletrônicos... Campinas: UNICAMP, 2001. Disponível em: http://alb.org.br/arquivomorto/edicoes_anteriores/anais13/arquivos/seminarios/pereira_luci.htm\#_ftnref1. Acesso em: 20 nov. 2020.

PEREIRA, Maria do Rosário Alves. Corpo feminino e envelhecimento na obra de Lygia Fagundes Telles. Estudos de Literatura Brasileira Contemporânea, Brasília, n. 56, p. 1-9, 2019. Disponível em: https://www.scielo.br/scielo.php?script=sci_arttext\&pid=S231640182019000100308. Acesso em: 17 ago. 2020.

SCHOLLHAMMER, Erik Karl. Ficção brasileira contemporânea. Rio de Janeiro: Civilização Brasileira, 2009.

TELLES, Lygia Fagundes. Boa noite, Maria. In: TELLES, Lygia Fagundes. A noite escura e mais eu. São Paulo: Rocco, 1998a, p. 55-78.

TELLES, Lygia Fagundes. Entrevista. Cadernos de Literatura Brasileira, São Paulo, Instituto Moreira Salles, n. 5, mar. 1998b.

SECCO, Carmen Lucia Tindó. Além da idade da razão: longevidade e saber na ficção brasileira. Rio de Janeiro: Graphia, 1994.

XAVIER, Elódia. Narrativa de autoria feminina na literatura brasileira: as marcas da trajetória. Leitura - Revista do Programa de Pós-Graduação em Letras, número especial de Literatura, Universidade Federal de Alagoas, n. 9, p. 87-95, 2. sem. 1996. 
WOLF, Naomi. O mito da beleza: como as imagens de beleza são usadas contra as mulheres. Rio de Janeiro: Rosa dos Tempos, 2018.

\section{NOTAS DE AUTORIA}

Maria do Rosário Alves Pereira (mariadorosario58@gmail.com) é Graduada em Letras, mestre em Letras Estudos Literários e doutora em Estudos Literários - área de concentração Literatura Brasileira, pela Universidade Federal de Minas Gerais. Professora dos cursos técnicos e de graduação em Letras no Centro Federal de Educação Tecnológica de Minas Gerais e professora na Pós-Graduação em Letras da Universidade Federal de Viçosa. Desenvolve pesquisas nas áreas de Literatura de autoria feminina, Literatura Brasileira e Edição.

Claudia Cristina Maia é (maiaclaudia@gmail.com) Graduada em Letras pela Universidade Federal de São João del-Rei, mestre em Literatura Brasileira pela Universidade Federal de Minas Gerais e Doutora em Literatura Comparada também pela Universidade Federal de Minas Gerais. Professora no Centro Federal de Educação Tecnológica de Minas Gerais. Desenvolve pesquisas nas áreas de Literatura Comparada e Literatura Brasileira.

\section{Agradecimentos}

Não se aplica.

\section{Como citar esse artigo de acordo com as normas da ABNT}

PEREIRA, Maria do Rosário Alves; MAIA, Claudia Cristina. Entre o dilaceramento e a alegria: considerações sobre a velhice na literatura brasileira de autoria feminina. Anuário de Literatura, Florianópolis, v. 26, p. 01$16,2021$.

\section{Contribuição de autoria}

Maria do Rosário A. Pereira: concepção, coleta de dados e análise de dados, elaboração do manuscrito, redação, discussão de resultados.

Claudia Cristina Maia: concepção, coleta de dados e análise de dados, elaboração do manuscrito, redação, discussão de resultados.

\section{Financiamento}

Não se aplica.

\section{Consentimento de uso de imagem}

Não se aplica.

\section{Aprovação de comitê de ética em pesquisa}

Não se aplica

\section{Conflito de interesses}

Não se aplica.

\section{Licença de uso}

Os/as autores/as cedem à Revista Anuário de Literatura os direitos exclusivos de primeira publicação, com o trabalho simultaneamente licenciado sob a Licença Creative Commons Attribution (CC BY) 4.0 International. Estra licença permite que terceiros remixem, adaptem e criem a partir do trabalho publicado, atribuindo 0 devido crédito de autoria e publicação inicial neste periódico. Os autores têm autorização para assumir contratos adicionais separadamente, para distribuição não exclusiva da versão do trabalho publicada neste periódico (ex.: publicar em repositório institucional, em site pessoal, publicar uma tradução, ou como capítulo de livro), com reconhecimento de autoria e publicação inicial neste periódico.

\section{Publisher}

Universidade Federal de Santa Catarina. Programa de Pós-graduação em Literatura. Publicação no Portal de Periódicos UFSC. As ideias expressadas neste artigo são de responsabilidade de seus/suas autores/as, não representando, necessariamente, a opinião dos/as editores/as ou da universidade. 


\section{Histórico}

Recebido em: 30/11/2020

Aprovado em: 11/03/2021

Publicado em: 28/10/2021 